\title{
Must we remain blind to undergraduate medical ethics education in Africa? A cross- sectional study of Nigerian medical students
}

\author{
Onochie Okoye ${ }^{1 *}$, Daniel Nwachukwu ${ }^{2}$ and Ferdinand C. Maduka-Okafor ${ }^{1}$
}

\begin{abstract}
Background: As the practice of medicine inevitably raises both ethical and legal issues, it had been recommended since 1999 that medical ethics and human rights be taught at every medical school. Most Nigerian medical schools still lack a formal undergraduate medical ethics curriculum. Medical education remains largely focused on traditional medical science components, leaving the medical students to develop medical ethical decision-making skills and moral attitudes passively within institutions noted for relatively strong paternalistic traditions.

In conducting a needs assessment for developing a curriculum germane to the Nigerian society, and by extension most of Sub-Saharan Africa, this study determined the views of Nigerian medical students on medical ethics education, ethical issues related to the doctor-patient relationship and the ethical/professional dilemmas they are confronted with.

Methods: Using self-administered 63-item structured questionnaires, a cross-sectional survey of the final year medical students of the University of Nigeria was conducted in July 2015. Using the Statistical Package for the Social Sciences software (SPSS Version 17), frequency counts and percentages were generated.

Results: The sample included 100 males (71.4\%) and 40 females (28.6\%), with the respective mean (SD) age being 24. 6(5.61) and 21.8 (6.38) years. Only 35.7\% were satisfied with their medical ethics knowledge, and $97.9 \%$ indicated that medical ethics should be taught formally. Only $8.6 \%$ had never witnessed a medical teacher act unethically. The dilemmas of poor communication between physicians and patients, and the provision of sub-standard care were reported highest for being encountered 'often'. A majority (60.7\%) indicated that "a doctor should do his best always, irrespective of the patient's wishes". No significant difference in responses across gender was noted.

Conclusion: There is a strong desire by the contemporary Nigerian medical student for medical ethics education. Their lack of exposure in medical ethics in an ethically challenging environment suggest a dire need for the development of an appropriate medical ethics curriculum for them and the provision of an ethically conducive learning environment.
\end{abstract}

Keywords: Medical ethics, Undergraduates, Curriculum, Education, Dilemma, Nigeria

\footnotetext{
*Correspondence: onochie.okoye@unn.edu.ng

'Department of Ophthalmology, College of Medicine, University of Nigeria,

Ituku-Ozalla, Enugu, Enugu State, Nigeria

Full list of author information is available at the end of the article
} 


\section{Background}

The practice of medicine in the modern era is beset with unprecedented challenges in virtually all cultures and societies [1].Medical students and resident doctors in training today are learning in an ethical environment that is increasingly complex. It is thus becoming imperative that the policies and processes being put in place to address this and other issues should guarantee a climate that is favourable and conducive to the ethical development of future medical practitioners [2].

With this changing role of medicine and the growing expectations by patients, the content and delivery of medical curricula also have to change [3].As part of this drive, it was recognised that medical ethics education should be accorded a greater formal presence in the medical curriculum [4]. By 1999, the World Medical Association's (WMA) 51st General Assembly had recommended that medical ethics and human rights be taught at every medical school as obligatory and examined parts of the medical curriculum; a resolution which was subsequently reinforced and revised in October 2015 [5] in recognition of the fact that the practice of good medicine inevitably raises both ethical and legal issues and demands an understanding of both [6].

In Nigeria, however, medical education remains largely focused on traditional clinical and basic medical science components, leaving students to develop moral attitudes passively through observation and intuition [7]; a situation that may not be too far from what it is obtainable in most of Sub-Saharan Africa [8-10]. There is evidence that the 'hidden' curriculum confers a powerful influence on the ethical and professional development of the students as they observe the norms, behaviours and interactions in their learning environments [4]; with the doctor-patient relationship being the predominant interaction.

There is still no formal medical ethics curriculum being seriously implemented in many Nigerian medical schools. Though medical ethics may exist as part of the curriculum in some of these schools, no curricular time is assigned. The apparent lack of institutional interest may be related to the lack of trained, capable faculty and the paucity of ethics educational resources and other infrastructures in these schools. Currently, there is no indigenous and locally available standardized undergraduate medical ethics text in the list of recommended textbooks within the Nigerian university system. More often than not, the only exposures for the medical students may be the informal ethics mentions by their supervising doctors in the course of their training, the occasional talks during their orientation programs or special events organised by the state chapter of the Nigerian Medical Association and also, media or internet reports on medico-ethical issues. Finally, on graduation, the newly inducted doctors are given the Code of Medical Ethics booklets together with their professional registration licenses but this still does not necessarily translate to a commensurate level of interest and knowledge [11].

There is no uniformity in what the students learn through the 'hidden' or 'informal' curricula, and there is no way of ensuring that a minimum standard is being met. The relative decline of ethical/professional standards, coupled with the deterioration of the doctor-patient relationship and the increasing criticisms of physicians by the public, have heightened the need for undergraduate medical ethics education. Current global best medical practices attach great importance to the concepts of informed consent and shared decision making, and these students need to be educated on the various models of the doctor-patient relationship; of which the universallyaccepted ideal remains the shared decision-making model. There is therefore a need to ensure that the medical schools can vouch for a minimum level of medical ethics knowledge, medico-ethical competencies, interactional skills set and, even the character of their graduates.

However, teaching medical ethics as merely a scientific body of knowledge may be dangerous if it misses the individualistic and communal perceptions of morality and ethics within their unique socio-economic, cultural, and geographic contexts [12]. In developed countries where it is being taught widely, medical ethics in its present form, remains largely rooted in western culture [10].Hence, the curriculum of medical ethics should be tailored to the local needs and peculiarities of the society where it is taught. In order to formulate a medical ethics curriculum germane to the six-year undergraduate medical degree program in Nigerian universities specifically, and most of Sub-Saharan Africa generally, educational needs assessment is imperative. As a preliminary step, this study was undertaken to determine the views of Nigerian medical students on medical ethics education and medico- ethical issues related to the doctorpatient relationship, as well as the ethical/professional dilemmas with which they may be confronted.

\section{Methods}

Using self-administered 63-itemstructured questionnaires, a cross-sectional survey of the final year medical students of the College of Medicine, University of Nigeria was conducted in July 2015 after a scheduled lecture. Eightyone items were initially generated from literature review [12-17] and emergent themes from previously conducted focus group discussions with pre-registration house-officers and junior resident doctors employed in the affiliated teaching hospital. In order to ensure some degree of validity, these items were consequently reviewed for relevance, appropriateness, difficulty and ambiguity by 3 senior medical educators/clinicians. The 63-item questionnaire was finally adopted, after 18 items were rejected. No prior 
information about the test items being tested was provided to them, and the questionnaires were retrieved immediately after completion at the venue; both measures aimed at minimising response bias. However, to reduce any possible misinterpretations of the test items arising from their brevity, the respondents were encouraged to seek clarifications on any item from the investigators. Such clarifications were provided openly to the entire sample very time.

The questionnaire had 4 major sections: the first section dealt with the socio-demographic data namely sex, age and religious affiliation; the second section with their views on 15 items regarding medical ethics education and their experience/witnessing of ethical dilemmas; the third section with their views on 10 clinical ethical issues related to the doctor-patient relationship and the fourth section on the frequency with which they witnessed selected 35 ethical/professional dilemmas. In section 2, the students were asked the following: if they had any previous formal exposure to medical ethics, if they were satisfied with their current knowledge of medical ethics, if medical ethics should be taught formally to medical students, if medical ethics should be a mandatory course and be assessed in medical schools, if medical ethics is best taught by medical doctors, if medical ethics is important for professional practice, if medical ethics is just 'common sense', if every medical student should be interested in medical ethics, if they had experienced an ethical dilemma, and if they had witnessed any teacher acting unethically. In addition, they were also required to indicate the following: their main type of formal medical ethics exposure, their main source of medical ethics information, the best time for introducing the teaching of medical ethics to medical students, the duration of formal ethics teaching required and the most important quality expected in medical ethics teachers. All the items required single responses to options provided.For instance, if the options provided for any item were 'Yes', 'No' and 'Not sure', or 'often', 'sometimes', 'never' and 'not sure,' the respondent was only required to select one response. The responses for the third section were ranked on a scale of 1 (Disagree), 2(not sure), and 3(Agree) and for the fourth section, options provided were 'often', 'sometimes' and 'never'. For section 3, the respondents were required to indicate their level of agreement with the perception statements provided. For three of the items, there were 'correct' answers we adopted i.e. bordering on the importance of confidentiality, consent being necessary for every procedure and the doctor doing his best for the patient always. For some other more contentious items, we sought to simply determine the baseline pattern of responses i.e. disclosure of medical errors to patients by their doctors. For sections 3 and 4,only single responses on all the test items were required, as well.
Data were then entered into an Excel database and using the Statistical Package for Social Sciences program version 17.0(SPSS inc), frequency counts and percentages were generated over the range of responses. The Chi-square test was used to determine the levels of significance, with $P$ values $<0.05$ being considered statistically significant. The study was approved by the Health Research Ethics Committee of the University of Nigeria Teaching Hospital, Ituku-ozalla, Enugu, Nigeria.

\section{Results}

The sample included 100males (71.4\%) and 40 females(28.6\%), with the respective mean (SD) age being 24.6(5.61) years and 21.8(6.38) years; a response rate of $91.5 \%$.The majority of these undergraduate medical students(62.1\%) were aged between 21 and 25 years. All the respondents were Christians, with the majority (44.3\%) belonging to the Roman catholic denomination.

Though the University does not run a formal training program in medical ethics, a majority of the students stated that they had been formally exposed in variable degrees to medical ethics within their undergraduate education; with a sizeable proportion of these students not being able to specify the type of formal exposure obtained and none being capable of specifying clearly the title of any medical ethics textbook read or didactic lecture ever received in school (Table 1).Among the 83 who stated that they had been formally taught medical ethics, a greater segment referred to the traditional onetime pre-clinical orientation talk for new clinical students as the main type of formal medical ethics teaching received (Table 1). An overwhelming majority of the 140 respondents $(97.9 \%)$ were of the view that medical ethics should be introduced and taught formally as a course (Table 2).A majority of the students (47.4\%) were in support of commencing the formal teaching of medical ethics in the clinical years, namely 3rd MBBS class(Pathology and Pharmacology as core subjects), 4th MBBS class (Paediatrics, Obstetrics \& Gynaecology, Community Medicine as core subjects) and 5th MBBS class(Medicine and Surgery as core subjects). Only 8.6\% had never witnessed a medical teacher act unethically, in their own perception (Table 1).Tables 1 and 2 present data on their views regarding the 15 test items in section 2 of the study questionnaire; mainly concerned with their exposure to medical ethics education, perception of medical ethics education and witnessing of ethical dilemmas. The responses of the students were also sought on some perception statements relevant to the doctor-patient relationship (Table 3). Their responses with respect to 'agree' and 'disagree' options were evenly distributed on three of the perception statements investigated, namely, "Children should never be treated without the consent of their parents/guardians", "Patients 
Table 1 Distribution of the 140 Students Regarding their Exposure to Medical Ethics(ME) Education and Ethical Dilemmas

\begin{tabular}{llll}
\hline Issue & Response & Number & $\%$ \\
\hline Previous formal exposure to ME & Yes & 83 & 59.3 \\
& No & 48 & 34.3 \\
& Not Sure & 9 & 6.4 \\
Main Type of ME exposure & Orientation talk & 38 & 45.8 \\
& Clinical teachings & 9 & 10.8 \\
& Special NMA lecture & 5 & 6.0 \\
& Not specified & 31 & 37.4 \\
Satisfied with ME knowledge & Yes & 50 & 35.7 \\
& No & 65 & 46.4 \\
& Not sure & 25 & 17.9 \\
Main ME information source & Media/internet & 76 & 54.3 \\
& Medical books & 44 & 31.4 \\
& Medical journals & 11 & 7.9 \\
& Clinical teachings & 1 & 0.7 \\
& Ethics textbooks & 0 & 0 \\
& Miscellaneous & 8 & 5.7 \\
& Didactic lectures & 0 & 0 \\
& Often & 18 & 12.9 \\
& Sometimes & 73 & 52.1 \\
Ethical dilemma experience & Never & 24 & 17.1 \\
& Not sure & 25 & 17.9 \\
& Often & 35 & 25 \\
Teachers' unethical conduct & Sometimes & 74 & 52.9 \\
& Never & 12 & 8.6 \\
& Not sure & 19 & 13.6 \\
\hline
\end{tabular}

Key: NMA-Nigerian Medical Association

Often-at least weekly

Sometimes-monthly/less frequently/seldom

Never-no incident experienced

should always be informed of every medical error" and "Close relatives should always be told about the patients' condition" (Table 3). Table 3 presents data relevant to the 10 test items in section 3 of the study questionnaire. The majority (60.7\%) were of the opinion that "a doctor should do his best always, irrespective of the patient's wishes" (Table 3). The dilemmas of poor communication between physicians and patients, and the provision of sub-standard care were reported highest with respect to being encountered 'often' (Table 4). Table 4 presents data from section 4 of the study questionnaire on the 35 test items regarding various ethical/professional dilemmas which were witnessed/encountered by these students. Comparisons done between the male and female respondents regarding their responses did not demonstrate any statistically significant difference.

\section{Discussion}

Medical ethics education is widely considered to have come of age [18].With ethics and professionalism being globally recognised as an integral component of the primary medical degree curriculum, it is presumed that early exposure of medical students may be beneficial in establishing a solid base in ethics [19].On this note, it seems that there is consensus that mainstreaming and formalising ethics education in the medical school curriculum increases knowledge and confidence in medical ethics among medical students [20].

Our study had a high response rate whereas, several related studies conducted in various parts of the world had recorded response rates ranging from $46.5 \%$ to $96 \%$ $[7,13,15,17,20-23]$; which may merely be a reflection of the levels of interest displayed by the various study populations or the types of study procedures adopted.Our study demonstrates a strong desire by these students for formal medical ethics education against the backdrop of the observed low level of their medical ethics education (Tables 1 and 2). This was further buttressed by the finding that the majority of the students were either not satisfied or uncertain about their knowledge in medical ethics. In another related study among final year medical students from the University of Ibadan, Nigeria, most students(80.5\%) responded that they did not receive enough training in medical ethics and $85.9 \%$ believed that formal ethics education would be worthwhile [7].Interestingly, a study conducted among Nigerian medical doctors demonstrated that $80 \%$ of the respondents admitted having some previous medical ethics education as undergraduates; with the median duration of exposure being three hours [11].However, $86 \%$ of these doctors deemed their exposure as grossly inadequate; a finding which is hardly surprising because most medical schools in Nigeria still have no formal medical ethics program. Several studies carried out among students and even physicians in many developing countries have also shown that the majority of their respondents expressed strong agreement on the importance of undergraduate medical ethics education $[15,19-21]$, even when being implemented minimally or inconsistently and with many of them making a case for properly structured medical ethics program across all levels of medical education.

The importance attached to a particular curricular element or activity may also be assessed by its position in the school calendar or the amount of time allocated. It is noteworthy that a greater proportion of our respondents expressed uncertainty over the ideal time for the introduction of medical ethics teaching or a preference for it to be introduced in the clinical phases of the medical program (Table 2). This may be an indication of their apparent perception of the existing medical curriculum as being already over-loaded, or their lack of information regarding the extent and scope of the proposed medical ethics curriculum. Some authors however opine that the first exposure of medical students to medical ethics should be within their first two years of school, and that it should be taught step by 
Table 2 Distribution of the 140 Medical Students Regarding their views on other Issues relevant to their need for Medical Ethics (ME) Education

\begin{tabular}{|c|c|c|c|}
\hline Issue & Response & Number & $\%$ \\
\hline $\begin{array}{l}\text { ME should be taught formally to } \\
\text { medical students }\end{array}$ & $\begin{array}{l}\text { Yes } \\
\text { No } \\
\text { Not sure }\end{array}$ & $\begin{array}{l}137 \\
2 \\
1\end{array}$ & $\begin{array}{l}97.9 \\
1.4 \\
0.7\end{array}$ \\
\hline $\begin{array}{l}\text { ME should be a mandatory course } \\
\text { and be assessed }\end{array}$ & $\begin{array}{l}\text { Yes } \\
\text { No } \\
\text { Not sure }\end{array}$ & $\begin{array}{l}123 \\
11 \\
6\end{array}$ & $\begin{array}{l}87.9 \\
7.9 \\
4.3\end{array}$ \\
\hline Best time to introduce the ME course & $\begin{array}{l}\text { 1st session } \\
\text { 2nd MB } \\
\text { class } \\
\text { 3rd MB class } \\
\text { 4th MB class } \\
\text { 5th MB class } \\
\text { Not sure }\end{array}$ & $\begin{array}{l}3 \\
14 \\
31 \\
23 \\
11 \\
55\end{array}$ & $\begin{array}{l}2.2 \\
10.2 \\
22.6 \\
16.8 \\
8 \\
40.1\end{array}$ \\
\hline Duration of ME teaching needed & $\begin{array}{l}\text { <one year } \\
\text { One year } \\
\text { >one year } \\
\text { Continuous } \\
\text { Not sure }\end{array}$ & $\begin{array}{l}22 \\
16 \\
29 \\
41 \\
32\end{array}$ & $\begin{array}{l}15.7 \\
11.4 \\
20.7 \\
29.3 \\
22.9\end{array}$ \\
\hline $\begin{array}{l}\text { The most important quality } \\
\text { in ME teachers }\end{array}$ & $\begin{array}{l}\text { Character } \\
\text { Competence } \\
\text { Any of the } 2 \\
\text { Others } \\
\text { Not sure }\end{array}$ & $\begin{array}{l}97 \\
18 \\
11 \\
2 \\
12\end{array}$ & $\begin{array}{l}69.3 \\
12.9 \\
7.9 \\
1.4 \\
8.6\end{array}$ \\
\hline ME is best taught by medical doctors & $\begin{array}{l}\text { Yes } \\
\text { No } \\
\text { Not sure }\end{array}$ & $\begin{array}{l}129 \\
2 \\
9\end{array}$ & $\begin{array}{l}92.1 \\
1.4 \\
6.4\end{array}$ \\
\hline ME is important for professional practice & $\begin{array}{l}\text { Yes } \\
\text { No } \\
\text { Not sure }\end{array}$ & $\begin{array}{l}132 \\
6 \\
2\end{array}$ & $\begin{array}{l}94.3 \\
4.3 \\
1.4\end{array}$ \\
\hline ME is just 'common sense' & $\begin{array}{l}\text { Yes } \\
\text { No } \\
\text { Not sure }\end{array}$ & $\begin{array}{l}41 \\
85 \\
14\end{array}$ & $\begin{array}{l}29.3 \\
60.7 \\
10\end{array}$ \\
\hline Every student should be interested in ME & $\begin{array}{l}\text { Yes } \\
\text { No } \\
\text { Not sure }\end{array}$ & $\begin{array}{l}130 \\
7 \\
3\end{array}$ & $\begin{array}{l}92.9 \\
5 \\
2.1\end{array}$ \\
\hline
\end{tabular}

The most important quality in ME teachers step throughout pre-clinical and clinical education [24, 25]. Since medical ethics is so important to medical education and practice, it should be vertically and horizontally integrated into the medical curriculum (starting preferably with a foundation course); a situation that may be in line with the views of a greater proportion of the students that the formal learning of medical ethics, once commenced,should continue for the entire duration of their medical program.

For the developing countries like Nigeria with peculiar challenges over malpractice and medical negligence, medical ethics education may actually be a process towards achieving the hitherto elusive regulation of medical practice [10].At a minimum, a more practical, pragmatic and measurable goal for the undergraduate medical ethics program may then be to endow our students with a set of cognitive and behavioural skills for ethical reasoning that will allow them to recognise ethical dilemmas in clinical practice and research, and equip them to reach socio-culturally sensitive, practical and ethically-defensible solutions to those dilemmas. Pertinent to any serious discussions about teaching medical ethics to undergraduate medical students in our setting will of course be consideration of issues such as determining the content areas, the specific objectives/ learning outcomes, the format for organising the contents, educational strategies according to Harden et al.'s model [4],teaching methods and assessment methods. The scope of this present study did not cover these important aspects with our respondents.

Significant gaps still remain in our understanding of the ways in which ethics curricula may contribute to improvements in the physician's ability to identify and handle ethical problems. Over the years, there has been a raging controversy on determining the concept of ethical sensitivity among medical students [26], though some posit that extensive curricular intervention in ethics teaching is effective for raising knowledge and confidence of medical

Table 3 Medical students responses to statements concerning the doctor-patient relationship $(n=140)$

\begin{tabular}{|c|c|c|c|}
\hline Perception statement & $\begin{array}{l}\text { Agree. } \\
\text { No(\%) }\end{array}$ & $\begin{array}{l}\text { Dis-agree. } \\
\text { No(\%) }\end{array}$ & Not sure. $\mathrm{No}(\%)$ \\
\hline Patient's wishes must be respected always & $84(60)$ & $41(29.3)$ & 15(10.7) \\
\hline Doctor should do his best irrespective of patient's wishes & $85(60.7)$ & $37(26.4)$ & 18(12.9) \\
\hline Confidentiality is not important in medical practice & 16(11.4) & 119(85) & $5(3.6)$ \\
\hline Consent is only necessary for surgeries and not for medical procedures or laboratory tests & $12(8.6)$ & 126(90) & 2(1.4) \\
\hline Close relatives should always be told about the patient's true medical condition or status & $51(36.4)$ & $59(42.1)$ & $30(21.4)$ \\
\hline Patients should always be informed by their doctor of every medical error & $55(39.3)$ & $58(41.4)$ & $27(19.3)$ \\
\hline Children should never be treated without the consent of their parents/guardians & $60(42.9)$ & $60(42.9)$ & 20(14.3) \\
\hline Patients refusing treatment on religious grounds should be referred elsewhere & $80(57.1)$ & $38(27.1)$ & $22(15.7)$ \\
\hline If patient wishes to die, doctors should assist to facilitate this & $10(7.1)$ & 113(80.7) & $17(12.1)$ \\
\hline Termination of pregnancy should be offered to any willing female who requests it & 20(14.3) & 104(74.3) & 16(11.4) \\
\hline
\end{tabular}


Table 4 Frequency with which the 140 students witnessed dilemmas related to issues of Decision-making for treatment, Justice, Communication, Professionalism and Student-Specific Concerns

\begin{tabular}{|c|c|c|c|}
\hline Dilemma & Often(\%) & Sometimes (\%) & Never(\%) \\
\hline $\begin{array}{l}\text { Poor Doctor/Patient communication } \\
\text { Substandard care being provided } \\
\text { Doctor/Patient care conflicts } \\
\text { Non-adherence to treatment } \\
\text { Decisional capacity concerns } \\
\text { Religious beliefs } \\
\text { Doctors going beyond professional obligations } \\
\text { Disrespect to colleagues, students } \\
\text { Doctors encouraging queue-jumping in clinic } \\
\text { Doctors disrespect to patients } \\
\text { Student keeping quiet over teachers conduct } \\
\text { Doctors treating despite poor prognosis } \\
\text { Students not allowed to examine patients } \\
\text { Student learning on patients unsupervised } \\
\text { Breaking bad news } \\
\text { Gratuitous story-telling about patients } \\
\text { Shortage of drugs/consumables } \\
\text { Student learning on patients without consent } \\
\text { Patients as research subjects } \\
\text { Informed consent issues } \\
\text { Student doing intimate physical examinations } \\
\text { Uncertainty over role in health team } \\
\text { Dealing with difficult patients } \\
\text { Medical/surgical error } \\
\text { Questionable use of resources } \\
\text { Discriminatory care of patients } \\
\text { Abuse /neglect of vulnerable persons } \\
\text { Student Compromising one's ethical standards } \\
\text { Privacy/confidentiality issues } \\
\text { Medical error disclosure } \\
\text { Blood transfusion concerns } \\
\text { Truth-telling vs deception } \\
\text { Surrogate decision making } \\
\text { Paternity test decisions } \\
\text { Do not resuscitate orders }\end{array}$ & $\begin{array}{l}64(45.7) \\
64(45.7) \\
48(43.3) \\
59(42.1) \\
55(39.3) \\
55(39.3) \\
54(38.6) \\
54(38.6) \\
54(38.6) \\
53(37.9) \\
51(36.4) \\
51(36.4) \\
50(35.7) \\
50(35.7) \\
42(30) \\
40(28.6) \\
40(28.6) \\
39(27.9) \\
37(26.4) \\
36(25.7) \\
36(25.7) \\
36(25.7) \\
35(25) \\
34(24.3) \\
29(20.7) \\
26(18.6) \\
26(18.6) \\
24(17.1) \\
23(16.4) \\
21(15) \\
19(13.6) \\
19(13.6) \\
14(10) \\
4(2.9) \\
3(2.1)\end{array}$ & $\begin{array}{l}63(45) \\
68(48.6) \\
85(60.7) \\
62(44.3) \\
79(56.4) \\
67(47.9) \\
74(52.9) \\
70(50) \\
72(51.4) \\
66(47.1) \\
75(53.6) \\
73(52.1) \\
66(47.1) \\
72(51.4) \\
79(56.4) \\
66(47.1) \\
69(49.3) \\
78(55.7) \\
70(50) \\
82(58.6) \\
69(49.3) \\
81(57.9) \\
69(49.3) \\
80(57.1) \\
43(30.7) \\
69(49.3) \\
73(52.1) \\
53(37.9) \\
72(51.4) \\
57(40.7) \\
104(74.3) \\
52(37.1) \\
55(39.3) \\
31(22.1) \\
19(13.6)\end{array}$ & $\begin{array}{l}13(9.3) \\
8(5.7) \\
7(5) \\
19(13.6) \\
6(4.3) \\
18(12.9) \\
12(8.6) \\
16(11.4) \\
14(10) \\
21(15) \\
14(10) \\
16(11.4) \\
24(17.1) \\
18(12.9) \\
19(13.6) \\
34(24.3) \\
31(22.1) \\
23(16.4) \\
33(23.6) \\
22(15.7) \\
35(25) \\
23(16.4) \\
36(25.7) \\
26(18.6) \\
68(48.6) \\
45(29.3) \\
41(29.3) \\
63(45) \\
45(32.1) \\
62(44.3) \\
17(12.1) \\
69(49.3) \\
71(50.7) \\
105(75) \\
118(84.3)\end{array}$ \\
\hline
\end{tabular}

Key: often-at least weekly

sometimes-monthly or less frequently/seldom

never-no incident experienced

students in facing ethical challenges [27]. In our study, the majority stated that they had experienced or witnessed ethical dilemmas in the course of their undergraduate program whereas $17.9 \%$ were not sure of having witnessed these challenges (Table 1); a possible pointer to their lack of confidence/ability in recognising moral issues. This particular study has demonstrated that these students commonly experience a wide range of ethical and professional challenges in the course of their medical education and clinical rotation (Table 4); bordering on decisionmaking over treatment/care, communication, professionalism issues, justice issues and student-specific issues as described in other studies $[28,29]$.The findings also bring to the fore the overlap between ethics and professionalism in healthcare; with medical professionalism being relevant to medical ethics as long as it concerns those attributes which foster health practitioners' abilities to recognise, interrogate, and to enact the ethical duties they possess in their roles [30]. The majority of the medical students stated that they had also witnessed a medical teacher acting unethically in the course of their program (Table 1).It must be stressed, however, that these students were merely reporting perceived unethical behaviour. They may not have had complete information or better insight into those witnessed acts which may really not have been unethical. Such clinical dilemmas can shape medical students' ethical and professional development and these experiences constitute an informal or 'hidden' ethics curriculum [31]. These clinical teachers who act as negative role models, especially those who show unethical behaviour towards patients, are the most frequently cited problematic aspects of the medical curriculum [31].If the gap between what is taught formally and what is practised or witnessed is wide, the message sent to the students becomes diluted, distorted and mis-interpreted; considering the fact that students sometimes also look for humanistic qualities in their teachers. Given the sensitive and controversial nature of many ethical issues in medical practice and education, the provision of an environment conducive to students' raising questions and expressing their opinions is imperative to 
promote genuine discourse on such issues; many of which may be largely unknown to their medical teachers. Without positive role-modelling and guidance, these students should not be expected to recognise, reason, acknowledge and act ethically through all ethical dilemmas confronting them all the time.

The range of their responses to the perception statements on doctor-patient relationship is indicative of the variation in the students' ethical sensitivity, depending on their knowledge, beliefs,values, experiences and interactions with their patients/attending doctors. The tension existing between the principles of respect for autonomy and beneficence (non-maleficence) and the tendency towards being paternalistic in the course of clinical decision-making is highlighted by the pattern of responses on the items addressing refusal of treatment on religious grounds, euthanasia/physician-assisted suicide and wilful termination of pregnancies; with socio-cultural and religious perspectives probably exerting their influences on these choices (Table 3).This could also be indicative of the lack of ethics training on the part of these students, who can only learn from the prevailing attitudes and practices of their medical teachers, most of whom apparently belong to the paternalistic traditions. In ethical dilemmas where conflicting values, preferences, principles, risks and benefits play out, a more structured analytical approach is imperative in achieving justifiable resolution. Without adequate ethics education, a vicious cycle of paternalism will invariably continue to dominate in the doctor-patient relationships in our settings.

For any effective medical ethics teaching program in our medical schools, efforts are needed to remove the impediments in the clinical educational environment, which may hinder the proper moral and professional development of these medical students [32]. A supportive system that is committed to the promotion of appropriate professional behaviour within our medical schools and the affiliated teaching/specialist hospitals remains the key to achieve this. The future of medical ethics education may not have to rely solely on formal curricular development but also in the creation of an ethical environment in which students can learn and honestly ask questions courageously, health workers can practise professionally and patients can receive humane care [33]. As part of the needs assessment, the views of other stakeholders such as the medical teachers, institutional and departmental heads, patients and other health care personnel may prove invaluable in developing an effective and appropriate medical ethics program for our medical schools. Inputs from the Medical and Dental Council of Nigeria (regulatory agency for medical practice), the National Universities Commission and the Nigerian Medical Association would also be essential to developing and implementing such curricula, not just for undergraduates but across all levels of medical education in the country.

\section{Conclusion}

This study has highlighted the strong desire by the contemporary Nigerian medical student for formal medical ethics education. Their lack of exposure in medical ethics in an ethically/professionally challenging environment highlights the need for the development of an appropriate medical ethics curriculum and the provision of an ethically conducive learning climate for positive role-modelling by the teachers and cultivation of moral courage by the students. In keeping in line with global best practices, the medical student in Nigeria, and by extension Africa, has definitely come of age to benefit from formal medical ethics teaching programs, and as such medical schools can no longer afford to remain blind to this development.

\section{Acknowledgements}

The authors wish to thank the MacLean Center and the authorities at the College of Medicine, University of Nigeria, as well as the entire final year class of 2015.

Funding
The research was entirely self-funded.

Availability of data and materials

The datasets used and analyzed during this study are available from the corresponding author on request.

\section{Authors' contributions}

$\mathrm{OIO}$ was responsible for the conception and design of the study whereas $\mathrm{OIO}$, DN and FCM participated in data collection, data analysis/interpretation, drafting of the manuscript, critical revision/final approval of the submitted version and the submission of the manuscript.

\section{Authors' information}

The authors are all senior lecturers at the medical school of the University of Nigeria, Enugu, Nigeria; OIO and FCM in the Department of Ophthalmology, and DN in the Physiology Department.OIO developed the concept as part of his undergraduate medical ethics curriculum project in the 2015/16 clinical ethics fellowship at the MacLean Center for Clinical Medical Ethics, University of Chicago, USA.

Ethics approval and consent to participate

The approval for the research was granted by the Health Research Ethics Committee of the University of Nigeria Teaching Hospital, ituku-ozalla, Enugu, Nigeria (NHREC/05/01/2008B-FWA00002458-IRB00002323.

Consent for publication

All the authors have given consent for publication.

Competing interests

The authors declare that they have no competing interests.

\section{Publisher's Note}

Springer Nature remains neutral with regard to jurisdictional claims in published maps and institutional affiliations.

\section{Author details}

'Department of Ophthalmology, College of Medicine, University of Nigeria, Ituku-Ozalla, Enugu, Enugu State, Nigeria. ${ }^{2}$ Department of Physiology, University of Nigeria, Enugu Campus, Enugu, Nigeria. 
Received: 28 October 2016 Accepted: 22 November 2017

Published online: 08 December 2017

\section{References}

1. ABIM Foundation. ACP-ASIM Foundation and European federation of internal medicine. Medical professionalism in the new millennium: a physician charter. Ann Intern Med. 2002;136:243-6.

2. Nicolaides $A$. The critical role of ethics training in medical education. 2014 www.ajhtl.com/uploads/7/1/6/3/7163688/article_22_vol. 3_1.pdf.Accessed 25 January 2015

3. Jones R, Higgs R, De Angelis C, Prideaux D. Changing face of medical curricula. Lancet. 2001;357:699-703.

4. Goldie J. Review of ethics curricula in undergraduate medical education. Med Educ. 2000:34:108-19.

5. World Medical Association.WMA resolution on the inclusion of medical ethics and human rights in the curriculum of medical schools world-wide. 2015. https://www.wma.net/policies-post/wma-resolution-on-the-inclusionof-medical-ethics-and-human-rights-in-the-curriculum-of-medical-schoolsworld-wide/

6. Stirrat GM, Johnston C, Gillon R, Boyd K, et al. Medical ethics and law for doctors of tomorrow: the 1998 consensus statement updated. J Med Ethics. 2010;36:55-60.

7. Ogundiran TO, Adebamowo CA. Medical ethics education:a survey of opinion of medical students in a Nigerian university.J Acad. Ethics. 2010;8(2):85-93.

8. Andoh CT. Bioethics education in Africa:still complex. Open Journal of Philosophy. 2013;3(4):507-16. https://doi.org/10.4236/ojpp.2013.34073

9. Coleman AME. Medical ethics and medical professionalism in low and middle income (LAMIC) countries: challenges and implications. Bangladesh Journal of Bioethics. 2015;6(2):1-7.

10. Ogundiran TO. Enhancing the African bioethics initiative. BMC Medical Education. 2004:4:21. https://doi.org/10.1186/1472-6920-4-21.

11. Fadare JO, Desalu OO, Jemilohun AC, Babatunde OA. Knowledge of medical ethics among Nigerian medical doctors. Niger Med J. Oct-Dec 2012;53(4):226-30.

12. Harihan S, Jonnalagadda R, Walrond E, Moseley H. Knowledge, attitude and practice of healthcare ethics and law among doctors and nurses in Barbados. BMC Medical Ethics. 2006;7:7. https://doi.org/10.1186/1472-6939-7-7.

13. Walrond ER, Jonnalagadda R, Harihuran S, Moseley HSL. Knowledge, attitudes and practice of medical students at the Cave Hill campus in relation to ethics and law in healthcare. West Indian Med J. 2006:55(1):42-7.

14. Monsudi KF, Oladele TO, Nasir AA, Ayanniyi AA. Medical ethics in subSaharan Africa:closing the gaps. Afr Health Sci. 2015:15(2):673-81.

15. Chatterjee B, Sarkar J. Awareness of medical ethics among undergraduates in a West Bengal medical college. Ind J Med Ethics Apr-Jun. 2012;9(2):93-9.

16. Hicks LK, Lin Y, Robertson DW, Woodrow SI. Understanding the clinical dilemmas that shape students' ethical development: questionnaire survey and focus group study. BMJ. 2001;322:709-10

17. Johnston C, Haughton P. Medical students perceptions of their ethics teaching J Med Ethics. 2007;33:418-22. https://doi.org/10.1136/jme.2006.018010.

18. Miles S, Lange L, Bickel J, Walker R, Cassel C. Medical ethics education: coming of age. Acad Med. 1989;64:705-14.

19. Ypinazar VA, Margolis SA. Western medical ethics taught to junior medical students can cross cultural and linguistic boundaries. BMC Medical Ethics. 2004;5:4. https://doi.org/10.1186/1472-6939-5-4

20. Chin JL, Voo TC, Abdulkarim SW. Chan Yk, Campbell AV. evaluating the effects of an integrated medical ethics curriculum on first year students. Ann Acad Med Singap. 2011:40:4-18.

21. Saled NH. Medical students attitudes to medical ethics education. Ann Coll Med Mosul Dec. 2013;39(2):101-6.

22. Asghari F, Samadi A, Dormohammadi T. Effectiveness of the course of medical ethics for undergraduate medical students. J Med Ethics Hist Med. 2009;2:7.

23. Parker MH, Price DA, Harris PG. Teaching of medical ethics: implications for an integrated curriculum. Med Educ. 1997;31:181-7.

24. Miyasaka M, Akabayashi A, Kai I, Ohi G. An international survey of medical ethics curricula in Asia. J Med Ethics. 1999;25:514-21.

25. Alkabba AF, Hussein GMA, Kasule OH, Jarallah J, Alrukban M, Alrashid A Teaching and evaluation methods of medical ethics in the Saudi public medical colleges: cross-sectional questionnaire study. BMC Medical Education. 2013;13:122

26. Hebert PC, Meslin EM, Dun EV Measuring the ethical sensitivity of medical students: a study at the University of Toronto. J Med Ethics. 1992;18:142-7.
27. Sulmasy D, Marx E. Ethics education for medical houseofficers: long-term improvement in knowledge and confidence. J Med Ethics. 1997;23:88-92.

28. Caldicott CV, Faber-Langendoen K. Deception, discrimination, and fear of reprisal: lessons in ethics from third-year medical students. Acad Med. 2005; 80(9):866-73.

29. Kaldjian LC, Rosenbaumm ME, Shinkunas LA, Woodhead JC, Antes LM, Rowat JA, Forman-Hoffman VL. Through students' eyes :ethical and professional issues identified by third year medical students during clerkships. J Med Ethics. 2012 Feb:38(2):130-2.

30. Dunn M. On the relationship between medical ethics and medical professionalism. J Med Ethics. 2016:42(10):625-6. https://doi.org/10.1136/ medethics-2016-103939

31. Hattab AS. Current trends in teaching ethics of healthcare practices. Developing World Bioethics. 2004;4(2):160-72.

32. Saltzburg L. Is the current state of medical ethics education having an impact on medical students? The Online Journal of Health Ethics. 2014; 10(2). http://dx.doi.org/10.18785/ojhe.1002.02.

33. Lehmann LS, Kasoff WS, Koch P, Federman DDA. Survey of medical ethics education at US and Canadian medical schools. Acad Med. 2004:79:682-9.

\section{Submit your next manuscript to BioMed Central and we will help you at every step:}

- We accept pre-submission inquiries

- Our selector tool helps you to find the most relevant journal

- We provide round the clock customer support

- Convenient online submission

- Thorough peer review

- Inclusion in PubMed and all major indexing services

- Maximum visibility for your research

Submit your manuscript at www.biomedcentral.com/submit 